\title{
Enhancement of antitumor immunity by combining anti-cytotoxic T lymphocyte antigen-4 antibodies and cryotreated tumor lysate-pulsed dendritic cells in murine osteosarcoma
}

\author{
MASANORI KAWANO, ICHIRO ITONAGA, TATSUYA IWASAKI and HIROSHI TSUMURA \\ Department of Orthopaedic Surgery, Faculty of Medicine, Oita University, Oita 879-5593, Japan
}

Received August 16, 2012; Accepted October 30, 2012

DOI: $10.3892 /$ or.2013.2224

\begin{abstract}
Immunotherapy with tumor lysate-loaded dendritic cells (DCs) is one of the most promising strategies to induce antitumor immune responses. However, the antitumor activity of cytotoxic $\mathrm{T}$ cells may be restrained by their expression of the inhibitory $\mathrm{T}$-cell coreceptor cytotoxic $\mathrm{T}$ lymphocyte antigen-4 (CTLA-4). By relieving this restraint, CTLA-4blocking antibodies promote tumor rejection, but the full scope of their most suitable applications has yet to be fully determined. In the present study, we offer proof of a preclinical concept in a $\mathrm{C} 3 \mathrm{H}$ mouse osteosarcoma (LM8) model that CTLA-4 blockade cooperates with cryotreated tumor lysatepulsed DCs in a primary tumor to prevent the outgrowth of lung metastasis. To evaluate immune response activation, we established the following four groups of $\mathrm{C} 3 \mathrm{H}$ mice $(60$ mice in total): i) control immunoglobulin $\mathrm{G}$ ( $\mathrm{IgG}$ )-treated mice; ii) tumor lysate-pulsed DC-treated mice; iii) anti-CTLA-4 antibody-treated mice and iv) tumor lysate-pulsed DC- and anti-CTLA-4 antibody-treated mice. The mice that received the tumor lysate-pulsed DCs and anti-CTLA-4 antibody displayed reduced numbers of regulatory $\mathrm{T}$ lymphocytes and increased numbers of $\mathrm{CD}^{+} \mathrm{T}$ lymphocytes inside the metastatic tumor, inhibition of metastatic growth, a prolonged lifetime, reduced numbers of regulatory $\mathrm{T}$ lymphocytes in the spleen and high serum interferon- $\gamma$ levels. Combining an anti-CTLA-4 antibody with tumor lysate-pulsed DCs enhanced the systemic immune response. To the best of our knowledge, these findings document for the first time an effect of the combination of tumor lysate-pulsed DCs and CTLA-4-blocking antibodies in osteosarcoma. We suggest that cryotreated tumor lysatepulsed DCs, although insufficient on their own, may mediate the rejection of metastatic lesions and prevent recurrence of
\end{abstract}

Correspondence to: Dr Masanori Kawano, Department of Orthopaedic Surgery, Faculty of Medicine, Oita University, Oita 879-5593, Japan

E-mail: kawano@oita-u.ac.jp

Key words: cytotoxic $\mathrm{T}$ lymphocyte antigen-4, dendritic cells, regulatory $\mathrm{T}$ cells, osteosarcoma the disease when combined with CTLA-4 blockade in osteosarcoma patients in the clinical setting.

\section{Introduction}

Osteosarcoma is the most common primary malignant tumor of bone. Remarkable advances in the treatment of osteosarcoma have occurred, including the introduction of adjuvant chemotherapy and appropriate surgical excision (1-4). However, there have also been advances in the field of immunotherapy for the treatment of osteosarcoma that have received less attention $(5,6)$. Following cryotreatment, the necrotic tumor lesion remains within the body, and the release of tumor antigens by dying cells has been hypothesized to activate a tumor-specific immune response via antigen presentation by antigen-presenting cells (APCs) such as dendritic cells (DCs) to T cells $(7,8)$. A number of tumor studies combining immunomodulation methods such as the injection of Toll-like receptor agonists with cryotreatment have demonstrated a synergistic effect on tumor rejection, and this was attributed to the enhanced activation of APC function $(9,10)$. We developed a method using cryotreated tumor tissue and DCs to enhance tumor-specific immunoreactions since DCs are the main APCs initiating cell-mediated immune responses in vivo $(11,12)$.

Monoclonal antibodies (mAbs) that block the function of cytotoxic T lymphocyte antigen-4 (CTLA-4), a transmembrane protein expressed by activated $\mathrm{T}$ cells, represent a promising novel therapy for treating cancer through the depletion of regulatory T cells (Tregs) (13-15). CTLA-4 inhibits the activation of self-reactive $\mathrm{T}$ cells, and several years ago blockade of this pathway was proposed to enhance tumor T-cell responses. As expected, in preclinical studies, CTLA-4 blockade led to tumor rejection (16-19). Clinical trials to validate the efficacy of anti-CTLA-4 mAb (anti-CTLA-4) therapy for the treatment of various types of cancers, including melanoma and prostate cancer, in humans have been completed or are currently underway $(20,21)$.

In the present study, we investigated how immunotherapies that target the inhibitory pathways of Tregs using anti-CTLA-4 mAbs potentially synergize the effects of cryotreated tumor lysate-pulsed DCs to generate systemic antitumor immunity. We verify that, in contrast to tumor lysate-pulsed DC or CTLA-4 treatment alone, the combination therapy enhanced antitumor 

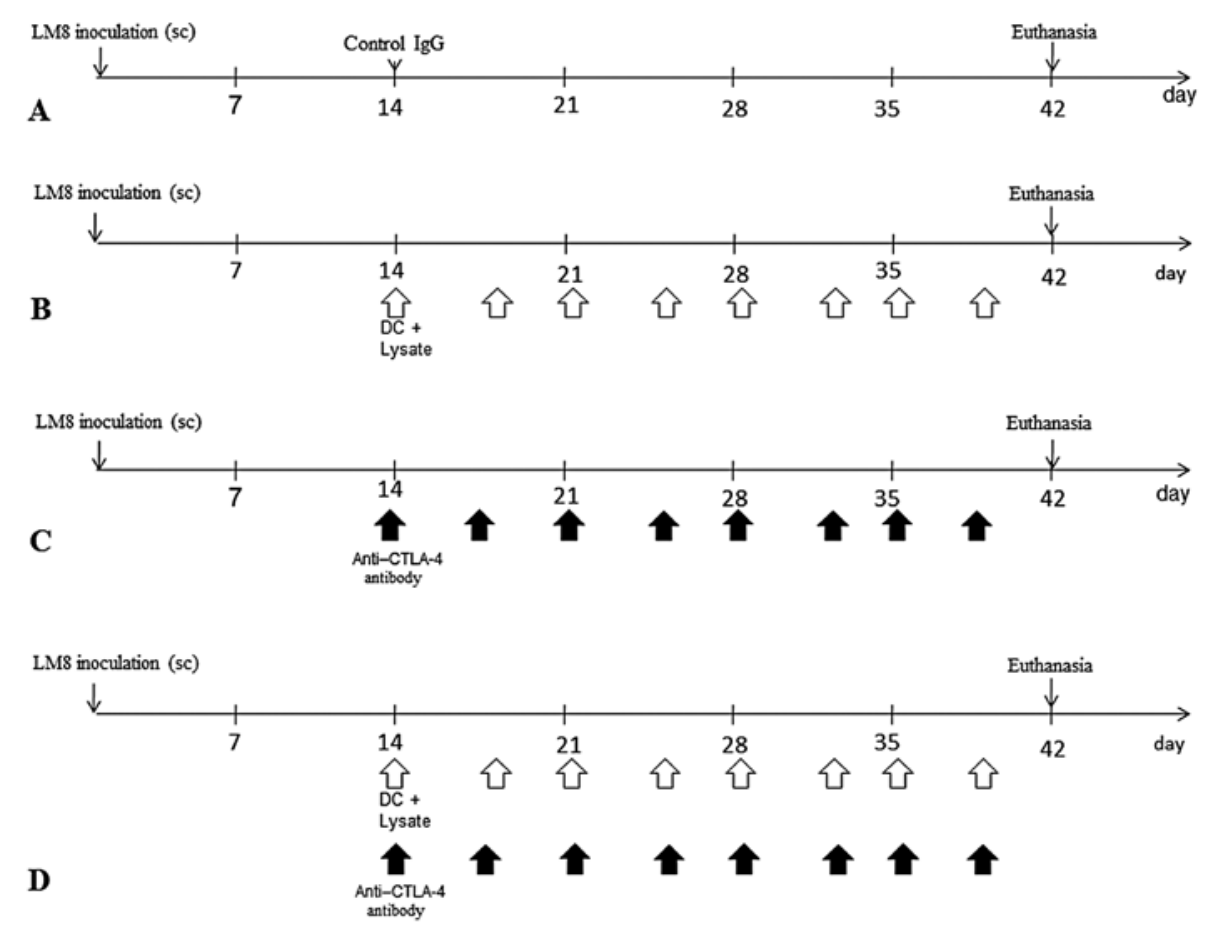

Figure 1. We established the following 4 groups: (A) Control IgG, (B) DC(Ly), (C) anti-CTLA-4 Ab and (D) DC(Ly) + anti-CTLA-4Ab. sc, subcutaneous.

immunity and slowed the growth of a secondary tumor from a large primary tumor by using a mouse metastatic osteosarcoma model.

\section{Materials and methods}

Cell line. LM8 cells, derived from Dunn osteosarcoma, were provided by the Riken BioResource Center (Saitama, Japan). The cells were maintained in complete medium consisting of RPMI-1640 supplemented with $10 \%$ heat-inactivated fetal bovine serum, $100 \mu \mathrm{g} / \mathrm{ml}$ streptomycin and $100 \mathrm{U} / \mathrm{ml}$ penicillin. Cells were cultured at $37^{\circ} \mathrm{C}$ in $5 \% \mathrm{CO}_{2}$.

Animals. A total of $1 \times 10^{6}$ LM8 cells (a murine osteosarcoma cell line) was hypodermically implanted into the subcutaneous gluteal region of 60 female $\mathrm{C} 3 \mathrm{H}$ mice 6-8 weeks old. We purchased the $\mathrm{C} 3 \mathrm{H}$ mice from Sankyo Labo, Inc. (Toyama, Japan) and housed them in a specific pathogen-free animal facility in our laboratory.

Study design. All animals developed tumors. The following 4 groups were established (Fig. 1): i) control immunoglobulin $\mathrm{G}(\mathrm{IgG})$ (control; $\mathrm{n}=15)$; ii) DCs exposed to cryotreated tumor lysates were injected twice a week into the subcutaneous contralateral gluteal region [DC(Ly); $n=15]$; iii) intraperitoneal injection of anti-CTLA-4 Ab was performed twice/week (anti-CTLA-4 Ab; $n=15$ ) and iv) DCs exposed to cryotreated tumor lysates were injected twice a week into the subcutaneous contralateral gluteal region and intraperitoneal injection of agonist anti-CTLA-4 antibody was performed twice/week [DC(Ly) + anti-CTLA-4 Ab; n=15]. This study was performed at the Department of Orthopaedic Surgery, Faculty of Medicine, Oita University, Oita, Japan. All experiments were performed under the guidelines for animal experiments as stipulated by the Oita University Graduate School of Medical Science.

Generation of DCs. Bone marrow-derived DCs were generated as described by Lutz and Rössner (22) with minor modifications. Briefly, erythrocyte-depleted mouse bone marrow cells obtained from flushed marrow cavities $\left(1 \times 10^{6}\right.$ cells $\left./ \mathrm{ml}\right)$ were cultured in complete medium with $20 \mathrm{ng} / \mathrm{ml}$ recombinant mouse granulocyte-macrophage colony-stimulating factor (GM-CSF) (PeproTech EC Ltd., London, UK) in 10-cm tissue culture dishes at $37^{\circ} \mathrm{C}$ in an atmosphere containing $50 \mathrm{ml} \mathrm{CO}_{2} / 1$.

Preparation of tumor lysate. Four weeks after tumor inoculation, we resected the primary tumor lesion and soaked the entire tumor in liquid nitrogen to kill the tumor cells. The freeze-thawed tumor lysate was added to the DC cultures on Day 6 at a ratio of 5 DC equivalents to 1 tumor cell (i.e., 5:1). The homogenate was passed through a $0.2-\mu \mathrm{m}$ filter to remove bacteria and tissues and mixed with the DCs for $24 \mathrm{~h}$. After $24 \mathrm{~h}$ of incubation, nonadherent cells including DCs were harvested by gentle pipetting.

Antibody. The monoclonal antibody CTLA-4 (hamster IgG, mCD152 antibody; $0.2 \mathrm{mg} / \mathrm{mouse}$ ) was provided by BioXcell (Lebanon, NH, USA). The CTLA-4 blocking activity was confirmed using the mink lung cell assay. The monoclonal control antibody IgG ( hamster IgG, isotype control antibodies; $0.2 \mathrm{mg} / \mathrm{mouse}$ ) was provided by BioXcell.

Flow cytometry. The markers Foxp3 and CD4, which are expressed on the surface of Tregs, were counted with a FACSCalibur $^{\mathrm{TM}}$ Flow Cytometer (Becton Dickinson, San Jose, CA, USA) and were stained with fluorochrome-conjugated 

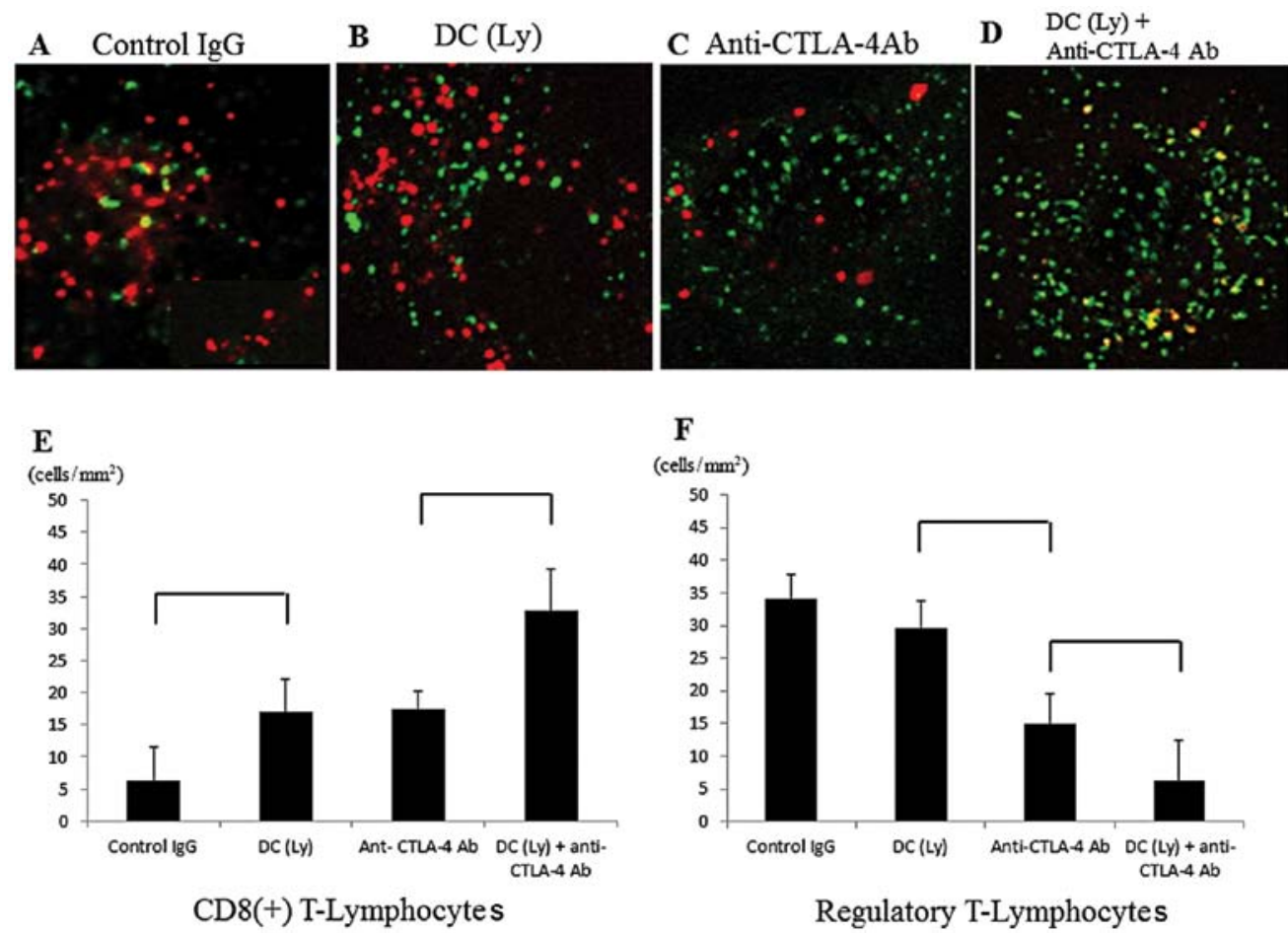

Figure 2. To evaluate $\mathrm{CD} 8^{+} \mathrm{T}$ lymphocytes and Tregs in pulmonary metastases, immunostaining was performed in the (A) control IgG, (B) DC(Ly), (C) agonist anti-CTLA-4 and (D) DC(Ly) with agonist anti-CTLA-4 Ab-treated groups. The number of CD8 ${ }^{+} \mathrm{T}$ lymphocytes (green) was increased and the Tregs (red) were decreased in the DC(Ly) and agonist anti-CTLA-4 Ab-treated group. The numbers of (E) CD8 ${ }^{+} \mathrm{T}$ lymphocytes and (F) Tregs/unit area in the 4 treatment groups are shown. Mice that were administered DC(Ly) + anti-CTLA-4 Ab demonstrated the highest level of CD8 ${ }^{+} \mathrm{T}$ lymphocytes and the lowest level of Tregs.

antibody (BD Pharmingen, Tokyo, Japan) for the following markers: phycoerythrin (PE)-conjugated anti-mouse Foxp3 staining kit (eBioscience, San Diego, CA, USA) and fluorescein isothiocyanate (FITC)-conjugated rat anti-mouse CD4 (BD Pharmingen; clone: RM4-5). Data analysis was performed with CellQuest $^{\mathrm{TM}}$ software (Becton Dickinson).

Immunofluorescence. Immunohistochemistry was used to measure the levels of Foxp3, a marker of Tregs, and CD8, a marker of cytotoxic $\mathrm{T}$ lymphocytes, within metastatic tumor lesions. Lung specimens were fixed in $20 \%$ formalin and embedded in paraffin. In each case, we examined all formalin-fixed, paraffin-embedded tumor tissue blocks. Five samples/mouse were cut into $4-\mu \mathrm{m}$ slices. Rehydrated tissue sections were incubated with primary Abs against $\mathrm{CD}^{+}$ (Santa Cruz Biotechnology, Santa Cruz, CA, USA) and Foxp3 (Abcam, Cambridge, MA, USA) diluted at 1:200 in Ab diluent (Dako ChemMate, Dako, Japan) overnight at room temperature. For $\mathrm{CD}^{+}$staining with FITC donkey anti-rabbit IgG and Foxp $^{+}$staining with Texas red goat anti-rat IgG (Invitrogen, Carlsbad, CA, USA), secondary antibodies were diluted at 1:300 in Ab diluent and added for $60 \mathrm{~min}$ at room temperature in the dark. Digital images were captured using a BIOREVO microscope equipped with a confocal microscopy system (BZ-9000; Keyence, Japan).

Tumor volume. Tumor volumes were measured using the micro-CT apparatus (R_mCT) to obtain high-resolution $\mathrm{CT}$ images in small living animals. The I-view-R (J. Morita Mfg Corp., Kyoto, Japan) was used as the viewer, and diagnosis was made with slice images viewed in all directions.
Tumor volumes were estimated using the formula ( $\pi$ x long axis $\mathrm{x}$ short axis $\mathrm{x}$ short axis)/6.

ELISA. We measured murine interferon- $\gamma($ IFN- $\gamma)$ and interleukin-10 (IL-10) release by enzyme-linked immunosorbent assay using Quantikine ${ }^{\circledR}$ (R\&D Systems, Minneapolis, MN, USA) according to the manufacturer's protocol using an Easy Reader EAR340 microtest plate reader (SLT-Lab Instruments, Salzburg, Austria).

Statistical analysis. We determined differences among the 4 groups using a non-repeated measures analysis of variance (ANOVA) and the Scheffe test. All analyses were conducted using SPSS ${ }^{\circledR} 18.0$ software (SPSS Japan, Inc., Tokyo, Japan). Results were expressed as the means \pm standard deviation and $\mathrm{P}<0.01$ was considered to indicate a statistically significant difference. For survival analysis, the differences in survival rates were analyzed by the log-rank test.

\section{Results}

Infiltration of $C D 8^{+}$T lymphocytes and Tregs inside the tumor. The levels of Foxp3 were significantly decreased and the numbers of $\mathrm{CD}^{+}$cells were significantly increased inside the metastatic tumor lesions in the anti-CTLA-4 antibody-treated groups. Foxp $3^{+}$cells were not recruited to the metastatic area in the anti-CTLA-4 antibody-treated groups compared with the findings in the control IgG-treated group (Fig. 2A-D). The number of $\mathrm{CD}^{+} \mathrm{T}$ lymphocytes/unit area was higher $(\mathrm{P}<0.01)$ in the mice that received tumor lysate-pulsed DCs and the anti-CTLA-4 antibody $\left(32.79 \pm 6.39\right.$ cells $\left./ \mathrm{mm}^{2}\right)$ compared to 


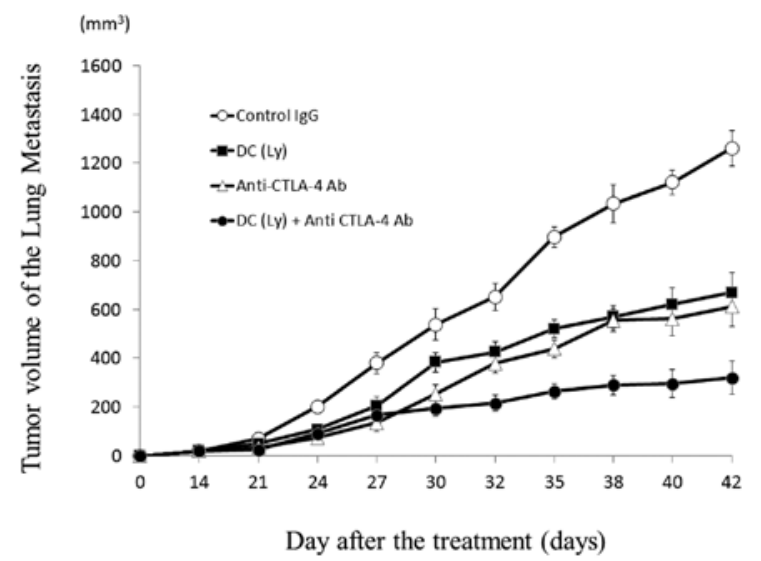

Figure 3. Tumor volumes of the lung metastases in the 4 treatment groups are shown using micro-CT.

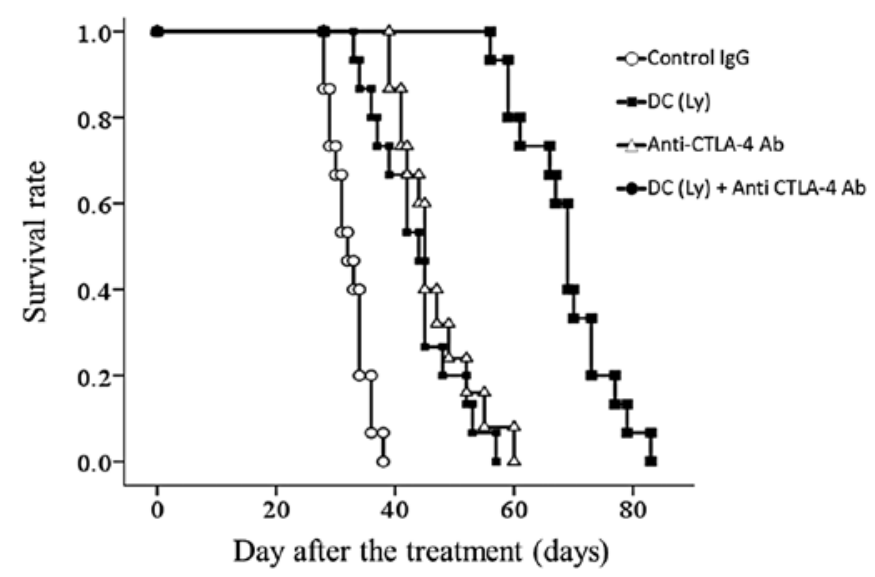

Figure 4. Survival rates of mice in each group. All mice in the IgG control group died of tumors at the inoculation site within 42 days. Survival was significantly prolonged in the DC(Ly) + anti-CTLA-4Ab group compared with the DC(Ly) alone or anti-CTLA-4 Ab alone groups based on the logrank test $(\mathrm{P}<0.001)$.

those that received tumor lysate-pulsed DCs $(16.98 \pm 5.16$ cells/ $\left.\mathrm{mm}^{2}\right)$ or anti-CTLA-4 antibody alone $\left(17.41 \pm 2.88 \mathrm{cells} / \mathrm{mm}^{2}\right.$; Fig. 2E). The number of Foxp3 ${ }^{+} \mathrm{T}$ lymphocytes/unit area was lower $(\mathrm{P}<0.01)$ in the mice that received the anti-CTLA- 4 antibody $\left(14.94 \pm 4.59\right.$ cells $\left./ \mathrm{mm}^{2}\right)$ compared to those that received tumor lysate-pulsed DCs $\left(29.54 \pm 4.22\right.$ cells $\left./ \mathrm{mm}^{2}\right)$. The number of Foxp $3^{+} \mathrm{T}$ lymphocytes/unit area was lower $(\mathrm{P}<0.01)$ in the mice that received tumor lysate-pulsed DCs and the antiCTLA4 antibody $\left(6.29 \pm 6.12\right.$ cells $\left./ \mathrm{mm}^{2}\right)$ compared to those that received the anti-CTLA-4 antibody alone (Fig. 2F).

Tumor volume of the lung metastases. Forty-two days after inoculation, the volume of the metastatic lesion $(\mathrm{P}<0.01)$ in the mice that received tumor lysate-pulsed DCs and the anti-CTLA-4 antibody $\left(319.58 \pm 49.96 \mathrm{~mm}^{3}\right)$ was lower compared to that in those that received tumor lysate-pulsed DCs $\left(669.04 \pm 40.19 \mathrm{~mm}^{3}\right)$ or the anti-CTLA-4 antibody alone $\left(611.54 \pm 31.97 \mathrm{~mm}^{3}\right)$ (Fig. 3).

Survival rate. The median survival time was: $\operatorname{IgG}$ control, 32.27 days (range, 28-38); tumor lysate-pulsed DC-treated

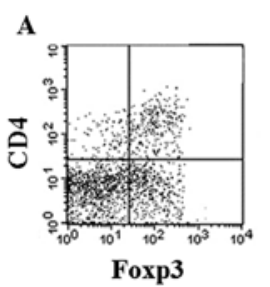

Control IgG

C

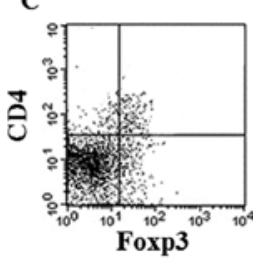

Anti-CTLA-4 Ab
B

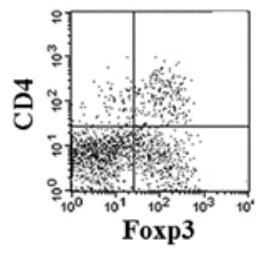

DC (Ly)

D

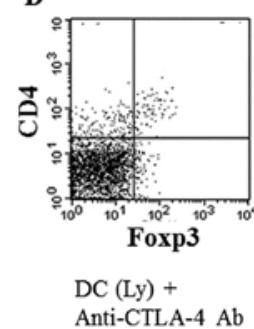

Figure 5. Ratio of $\mathrm{CD}^{+}$(stained with FITC fluorochrome-conjugated rat anti-mouse CD4 antibody) and Foxp3 ${ }^{+}$(stained with PE fluorochromeconjugated anti-mouse Foxp 3 antibody) $\mathrm{T}$ cells in the spleen 42 days after tumor inoculation was measured using flow cytometry in the (A) control IgG (B) DC(Ly)-, (C) agonist anti-CTLA-4 Ab- and (D) DC(Ly) with agonist anti-CTLA-4 Ab-treated groups. CD $4^{+} \mathrm{Foxp}^{+} \mathrm{T}$ cells were decreased in the agonist anti-CTLA-4-treated group.
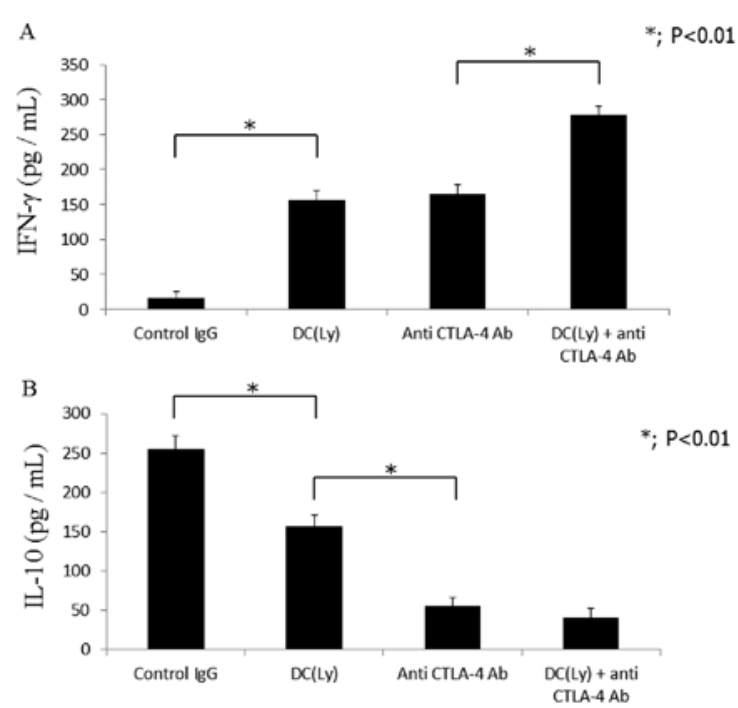

Figure 6. (A) Mice that were administered DC(Ly) + agonist anti-CTLA-4 $\mathrm{Ab}$ showed the highest IFN- $\gamma$ level. (B) Mice that were administered DC(Ly) + agonist anti-CTLA-4 Ab demonstrated the lowest IL-10 level.

group, 43.47 days (range, 33-57); anti-CTLA4 antibodytreated group, 45.93 days (range, 39-60) and for the tumor lysate-pulsed DCs and the anti-CTLA-4 antibody group, 68.67 days (range, 56-83). All mice in the control IgG group were sacrificed within 42 days following formation of an enlarged tumor at the inoculated site. Survival was significantly prolonged but differences in the tumor lysate-pulsed DCs alone and the anti-CTLA4 antibody alone groups were small compared with the control $\operatorname{IgG}$ group $(\mathrm{P}<0.001)$. There was no significant difference between the tumor lysate-pulsed DCs alone and anti-CTLA4 antibody alone groups. Further lifetime prolongation was observed in the tumor lysate-pulsed 
DCs and anti-CTLA-4 antibody group compared with the tumor lysate-pulsed DCs alone and anti-CTLA4 antibody alone groups $(\mathrm{P}<0.01)$ (Fig. 4.).

Reduction of Tregs in the spleen. The anti-CTLA-4 antibody markedly reduced the cell population of Tregs, the 2 markers of which are $\mathrm{CD}^{+}$and $\mathrm{Foxp}^{+}$, in the spleen. The groups that received anti-CTLA-4 antibody alone (Fig. 5C) or in combination with tumor lysate-pulsed DCs (Fig. 5D) displayed marked decreases in the percentage of $\mathrm{CD} 4{ }^{+} \mathrm{Foxp} 3^{+}$cells compared with the findings in the control IgG (Fig. 5A) or tumor lysatepulsed DC-treated group (Fig. 5B).

Cytokine release. Mice treated with tumor lysate-pulsed DCs and the anti-CTLA-4 antibody displayed higher serum IFN- $\gamma$ levels $(278.33 \pm 18.64 \mathrm{pg} / \mathrm{ml} ; \mathrm{P}<0.01)$ compared to those that received tumor lysate-pulsed DCs $(129.6 \pm 13.28 \mathrm{pg} / \mathrm{ml})$ or the anti-CTLA4 antibody alone $(126.98 \pm 20.37 \mathrm{pg} / \mathrm{ml})$ (Fig. 6A). Serum IL-10 levels were lower $(\mathrm{P}<0.01)$ in the mice that received the anti-CTLA-4 antibody alone $(53.24 \pm 21.29 \mathrm{pg} / \mathrm{ml})$ compared to those that received tumor lysate-pulsed DCs alone $(145.43 \pm 16.38 \mathrm{pg} / \mathrm{ml})$. Serum IL-10 levels were lower $(\mathrm{P}<0.01)$ in the mice that received tumor lysate-pulsed DCs and the anti-CTLA4 antibody $(15.38 \pm 9.26 \mathrm{pg} / \mathrm{ml})$ compared to those that received the anti-CTLA-4 antibody alone (53.24 $\pm 21.29 \mathrm{pg} / \mathrm{ml})$ (Fig. 6B).

\section{Discussion}

Most osteosarcoma patients are treated with a combination of surgery and chemotherapy. Despite recent advances in local therapy with curative intent, chemotherapeutic treatments for metastatic disease often remain unsatisfactory owing to severe adverse effects and incomplete long-term remission. Therefore, the evaluation of novel therapeutic options is of great interest. Since the discovery of the regression of metastases after cryotreatment, investigators have examined immune responses in animal models in hopes of showing a 'cryoimmunologic' effect $(12,23-25)$. Despite the lack of response to cryotreatment alone, we observed a synergistic effect when cryotreatment was combined with DCs (11). Since the initial discovery that CTLA-4 stimulation drives T-cell immunity (13-15), anti-CTLA-4 therapy has been used extensively for tumor immunotherapy. In addition, CTLA-4 stimulation has been demonstrated to suppress the function of Treg cells and drive potent $\mathrm{CD}^{+} \mathrm{T}$ cell-mediated tumor protection (16-19). However, the synergistic effect of anti-CTLA-4 antibody and cryotreated tumor lysate-pulsed DCs has not been investigated in osteosarcoma models. In the present study, we examined the synergistic effect of cryotreated tumor lysate-pulsed DCs and CTLA-4 blockade on preventing the development of a secondary tumor from a large primary tumor by using a mouse metastatic osteosarcoma model.

The anti-CTLA-4 antibody inhibited the accumulation of Tregs and induced the infiltration of $\mathrm{CD}^{+} \mathrm{T}$ cells inside the metastatic lesions. CTLA-4 signaling in CD $4^{+}$Foxp $3^{+}$Tregs is required for their immunosuppressive capacity $(13,16)$. Our findings revealed that CTLA-4 stimulation led to the inhibition of Foxp3 $3^{+} \mathrm{T}$ cells inside the tumor tissues. We report that after combination therapy, the numbers of intratumoral
$\mathrm{CD}^{+} \mathrm{T}$ cells were significantly increased and Treg cells were depleted by the combination treatment, supporting the ability of the therapy to enhance the tumor-specific cell mediated immune response.

The group treated with the combination of tumor lysatepulsed DCs and the anti-CTLA-4 antibody also displayed smaller lung metastases with a prolonged lifetime. Tregs comprise one of the major components of the immunosuppressive condition of tumor lesions (15). Noteworthy, the result of tumor rejection in lung metastatic lesions in the combined therapy group correlated with the intratumor ratio of $\mathrm{CD}^{+}$ $\mathrm{T}$ cells to Tregs. This suggests that controlling immunosuppressive factors may facilitate the activity of DCs and cytotoxic $\mathrm{T}$ lymphocytes in the tumor. Identically, the Treg depletion using anti-CTLA-4 antibody treatment combined with tumor lysate-pulsed DCs treatment displayed a significantly improved survival in comparison to the tumor lysate-pulsed DCs or anti-CTLA-4 antibody monotherapy groups.

The combination therapy also resulted in the enhancement of the number of $\mathrm{CD}^{+} \mathrm{T}$ cells and prevented the proliferation of Tregs in the spleen, which is evidence of a systemic response with the potential to eradicate disseminated disease. Inhibition of Treg accumulation in the spleen enhances systemic cellmediated immunity through the activation of DCs or cytotoxic T lymphocytes.

Tumor lysate-pulsed DCs and CTLA-4 blockade induced the activation of cell-mediated immunity by increasing serum IFN- $\gamma$ levels and decreasing serum IL-10 levels. Tregs are among the major elements that cause potent immunosuppression mediated by cytokines from tumor cells and the inhibition of CTLA-4 stimulation may be useful for enhancing the efficacy of cancer therapy or vaccines (26-28). Our results revealed that blocking CTLA-4 signaling using anti-CTLA-4 antibody enhanced cell-mediated immunity.

Although the immune response to tumor lysate-pulsed DCs or anti-CTLA-4 antibody alone may vary or may be insufficient to suppress metastatic tumors, the combination of tumor lysatepulsed DCs and CTLA-4 blockade has the potential to create a robust antitumor immune response that controls the growth of metastases. The present study could lead to a generation of proposals for clinical trials, in which tumor lysate-pulsed DCs will be combined with CTLA-4 blockade to treat cancer. Ipilimumab is a human monoclonal immunoglobulin $\mathrm{G}(\mathrm{IgG})$ antibody against CTLA-4, an immune inhibitory molecule that the US Food and Drug Administration has approved for the treatment of unresectable or metastatic melanoma in 2011 (29). The combination of ipilimumab and chemotherapy in the treatment of melanoma (30) and lung cancer (31) has been evaluated in clinical trials.

Chemotherapy for human osteosarcoma is the standard treatment and it should be performed before immunotherapy. However, additional methods have yet to be developed for treating patients who are resistant to the standard osteosarcoma treatment (32). Therefore, the development of novel treatment strategies for metastatic osteosarcoma is critical. The combination of chemotherapy, DC vaccination and antiCTLA-4 antibody treatment may be effective in the treatment of osteosarcoma patients with residual tumors or distant metastasis after chemotherapy. These issues will be addressed in the future to enable the clinical application of our therapy in 
treating human osteosarcoma and to facilitate further research efforts.

\section{Acknowledgements}

We thank Hiroyuki Tsuchiya, Hideji Nishida, Katsuhiro Hayashi, Akihiko Takeuchi and Katsuro Tomita for participating in this study.

\section{References}

1. Ferrari S, Smeland S, Mercuri M, et al: Neoadjuvant chemotherapy with high-dose ifosfamide, high-dose methotrexate, cisplatin, and doxorubicin for patients with localized osteosarcoma of the extremity: a joint study by the Italian and Scandinavian Sarcoma Groups. J Clin Oncol 23: 8845-8852, 2005.

2. Kager L, Zoubek A, Dominkus M, Lang S, Bodmer N, Jundt G, Klingebiel T, Jürgens H, Gadner H and Bielack S; COSS Study Group: Osteosarcoma in very young children: experience of the Cooperative Osteosarcoma Study Group. Cancer 116: 5316-5324, 2010.

3. Lewis VO: What's new in musculoskeletal oncology. J Bone Joint Surg Am 89: 1399-1407, 2007.

4. Stiller CA, Bielack SS, Jundt G and Steliarova-Foucher E: Bone tumours in European children and adolescents, 1978-1997. Report from the Automated Childhood Cancer Information System project. Eur J Cancer 42: 2124-2135, 2006.

5. Campbell CJ, Cohen J and Enneking WF: Editorial: New therapies for osteogenic sarcoma. J Bone Joint Surg Am 57: $143-144,1975$

6. Kawaguchi S, Wada T, Tsukahara T, Ida K, Torigoe T, Sato N and Yamashita T: A quest for therapeutic antigens in bone and soft tissue sarcoma. J Transl Med 3: 31, 2005.

7. Soanes WA, Ablin RJ and Gonder MJ: Remission of metastatic lesions following cryosurgery in prostatic cancer: immunologic considerations. J Urol 104: 154-159, 1970.

8. Sabel MS: Cryo-immunology: a review of the literature and proposed mechanisms for stimulatory versus suppressive immune responses. Cryobiology 58: 1-11, 2009.

9. Kawano M, Nishida H, Nakamoto Y, Tsumura $\mathrm{H}$ and Tsuchiya $\mathrm{H}$ : Cryoimmunologic antitumor effects enhanced by dendritic cells in osteosarcoma. Clin Orthop Relat Res 468: 1373-1383, 2010.

10. Nishida H, Tsuchiya $\mathrm{H}$ and Tomita $\mathrm{K}$ : Re-implantation of tumour tissue treated by cryotreatment with liquid nitrogen induces antitumour activity against murine osteosarcoma. J Bone Joint Surg Br 90: 1249-1255, 2008.

11. den Brok MH, Sutmuller RP, Nierkens S, Bennink EJ, Toonen LW, Figdor CG, et al: Synergy between in situ cryoablation and TLR9 stimulation results in a highly effective in vivo dendritic cell vaccine. Cancer Res 66: 7285-7292, 2006.

12. Redondo P, del Olmo J, López-Diaz de Cerio A, Inoges S, Marquina M, Melero I and Bendandi M: Imiquimod enhances the systemic immunity attained by local cryosurgery destruction of melanoma lesions. J Invest Dermatol 127: 1673-1680, 2007.

13. Wing K, Onishi Y, Prieto-Martin P, et al: CTLA-4 control over $\mathrm{Foxp}^{+}$regulatory T cell function. Science 322: 271-275, 2008.

14. Liang B, Workman C, Lee J, et al: Regulatory T cells inhibit dendritic cells by lymphocyte activation gene-3 engagement of MHC class II. J Immunol 180: 5916-5926, 2008.

15. Viguier M, Lemaître F, Verola O, et al: Foxp3 expressing $\mathrm{CD} 4{ }^{+} \mathrm{CD} 25$ (high) regulatory $\mathrm{T}$ cells are overrepresented in human metastatic melanoma lymph nodes and inhibit the function of infiltrating T cells. J Immunol 173: 1444-1453, 2004.

16. Leach DR, Krummel MF and Allison JP: Enhancement of antitumor immunity by CTLA-4 blockade. Science 271: 1734-1736, 1996.
17. Hurwitz AA, Yu TF, Leach DR and Allison JP: CTLA-4 blockade synergizes with tumor-derived granulocyte-macrophage colonystimulating factor for treatment of an experimental mammary carcinoma. Proc Natl Acad Sci USA 95: 10067-10071, 1998.

18. van Elsas A, Hurwitz AA and Allison JP: Combination immunotherapy of B16 melanoma using anti-cytotoxic $\mathrm{T}$ lymphocyte-associated antigen 4 (CTLA-4) and granulocyte/ macrophage colony-stimulating factor (GM-CSF)-producing vaccines induces rejection of subcutaneous and metastatic tumors accompanied by autoimmune depigmentation. J Exp Med 190: 355-366, 1999.

19. Demaria S, Kawashima N, Yang AM, Devitt ML, Babb JS, Allison JP and Formenti SC: Immune-mediated inhibition of metastases after treatment with local radiation and CTLA-4 blockade in a mouse model of breast cancer. Clin Cancer Res 11: 728-734, 2005.

20. Small EJ, Sacks N, Nemunaitis J, Urba WJ, Dula E, Centeno AS, et al: Granulocyte macrophage colony-stimulating factor-secreting allogeneic cellular immunotherapy for hormone-refractory prostate cancer. Clin Cancer Res 13: 3883$3891,2007$.

21. Hodi FS, O'Day SJ, McDermott DF, Weber RW, Sosman JA, Haanen JB, et al: Improved survival with ipilimumab in patients with metastatic melanoma. N Engl J Med 363: 711-723, 2010.

22. Lutz MB and Rössner S: Factors influencing the generation of murine dendritic cells from bone marrow: the special role of fetal calf serum. Immunobiology 212: 855-862, 2007.

23. Sabel MS, Arora A, Su G and Chang AE: Adoptive immunotherapy of breast cancer with lymph node cells primed by cryoablation of the primary tumor. Cryobiology 53: 360-366, 2006.

24. Sabel MS, Nehs MA, Su G, Lowler KP, Ferrara JLM and Chang AE: Immunologic response to cryoablation of breast cancer. Breast Cancer Res Treat 90: 97-104, 2005.

25. Urano M, Tanaka C, Sugiyama Y, Miya K and Saji S: Antitumor effects of residual tumor after cryoablation: the combined effect of residual tumor and a protein-bound polysaccharide on multiple liver metastases in a murine model. Cryobiology 46: 238-245, 2003.

26. Yang YF, Zou JP, Mu J, Wijesuriya R, Ono S, Walunas T, Bluestone J, Fujiwara $\mathrm{H}$ and Hamaoka T: Enhanced induction of antitumor T-cell responses by cytotoxic $\mathrm{T}$ lymphocyteassociated molecule-4 blockade: the effect is manifested only at the restricted tumor-bearing stages. Cancer Res 57: 4036-4041, 1997.

27. Persson J, Beyer I, Yumul R, et al: Immuno-therapy with antiCTLA4 antibodies in tolerized and non-tolerized mouse tumor models. PLoS One 6: 22303, 2011.

28. Shrikant P, Khoruts A and Mescher MF: CTLA-4 blockade reverses $\mathrm{CD}^{+} \mathrm{T}$ cell tolerance to tumor by a $\mathrm{CD} 4^{+} \mathrm{T}$ cell- and IL-2-dependent mechanism. Immunity 11: 483-493, 1999.

29. Traynor K: Ipilimumab approved for metastatic melanoma. Am J Health Syst Pharm 68: 768, 2011.

30. Hersh EM, O'Day SJ, Powderly J, et al: A phase II multicenter study of ipilimumab with or without dacarbazine in chemotherapy-naïve patients with advanced melanoma. Invest New Drugs 29: 489-498, 2011.

31. Lynch TJ, Bondarenko I, Luft A, Serwatowski P, Barlesi F, Chacko R, Sebastian M, Neal J, Lu H, Cuillerot JM and Reck M: Ipilimumab in combination with paclitaxel and carboplatin as first-line treatment in stage IIIB/IV non-small-cell lung cancer: results from a randomized, double-blind, multicenter phase II study. J Clin Oncol 30: 2046-2054, 2012.

32. Bacci G, Briccoli A, Rocca M, Ferrari S, Donati D, Longhi A, Bertoni F, Bacchini P, Giacomini S, Forni C, Manfrini M and Galletti S: Neoadjuvant chemotherapy for osteosarcoma of the extremities with metastases at presentation: recent experience at the Rizzoli Institute in 57 patients treated with cisplatin, doxorubicin, and a high dose of methotrexate and ifosfamide. Ann Oncol 14: 1126-1134, 2003. 